\title{
The myth of nitric oxide in central cardiovascular control by the nucleus tractus solitarii
}

W.T. Talman

\author{
Correspondence \\ W.T. Talman \\ Department of Neurology \\ University of lowa \\ lowa City, IA 52242 \\ USA \\ Fax: 001-(319)-356-4505 \\ E-mail: william-talman@uiowa.edu
}

Presented at the International Symposium "Neuroendocrine Control of Body Fluid Homeostasis",

Ribeirão Preto, SP, Brasil,

August 17-20, 1996.

Research supported in part by a Department of Veterans Affairs Clinical Investigatorship and Merit Review and by the National Institutes of Health (NIH Nos. R01-HL32205 and PO1-HL14388).

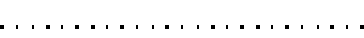

Received August 26, 1996 Accepted October 9, 1996 $\ldots \ldots \ldots \ldots \ldots \ldots$
Department of Veterans Affairs Medical Center and Departments of Neurology and Neuroscience, University of lowa, lowa City, IA 52242, USA

\begin{abstract}
Considerable evidence suggests that nitroxidergic mechanisms in the nucleus tractus solitarii (NTS) participate in cardiovascular reflex control. Much of that evidence, being based on responses to nitric oxide precursors or inhibitors of nitric oxide synthesis, has been indirect and circumstantial. We sought to directly determine cardiovascular responses to nitric oxide donors microinjected into the NTS and to determine if traditional receptor mechanisms might account for responses to certain of these donors in the central nervous system. Anesthetized adult Sprague Dawley rats that were instrumented for recording arterial pressure and heart rate were used in the physiological studies. Microinjection of nitric oxide itself into the NTS did not produce any cardiovascular responses and injection of sodium nitroprusside elicited minimal depressor responses. The S-nitrosothiols, Snitrosoglutathione (GSNO), S-nitrosoacetylpenicillamine (SNAP), and S-nitroso-D-cysteine (D-SNC) produced no significant cardiovascular responses while injection of S-nitroso-L-cysteine (L-SNC) elicited brisk, dose-dependent depressor and bradycardic responses. In contrast, injection of glyceryl trinitrate elicited minimal pressor responses without associated changes in heart rate. It is unlikely that the responses to L-SNC were dependent on release of nitric oxide in that 1) the responses were not affected by injection of oxyhemoglobin or an inhibitor of nitric oxide synthesis prior to injection of L-SNC and 2) Land D-SNC released identical amounts of nitric oxide when exposed to brain tissue homogenates. Although GSNO did not independently affect blood pressure, its injection attenuated responses to subsequent injection of L-SNC. Furthermore, radioligand binding studies suggested that in rat brain synaptosomes there is a saturable binding site for GSNO that is displaced from that site by L-SNC. The studies suggest that S-nitrosocysteine, not nitric oxide, may be an interneuronal messenger for cardiovascular neurons in the NTS.
\end{abstract}

Key words

- Nitric oxide

- Nucleus tractus solitarii

- Cardiovascular control

- Receptors

- Nitrosothiol 
Over the past 15 years a new concept of signal transduction has arisen as a result of studies suggesting that the radical nitric oxide (NO.), generated by constitutive nitric oxide synthase (NOS), may participate in endothelium-derived relaxation (1), inhibition of platelet aggregation (2), and interneuronal transmission of signals (3). A soluble gas passing freely through cell membranes to act at the cytoplasmic enzyme soluble guanylate cyclase (sGC), which served as a "receptor" (4), was considered extraordinary $(5,6)$ but gained wide acceptance (6). Now there are numerous studies that support an important role for NO- in synaptic transmission both in the central and in the peripheral nervous system $(3,7)$. While the understanding of signal transduction mechanisms underlying such transmission is incomplete, activation of sGC with formation of cyclic GMP (cGMP) is known to play a role (8).

Earlier studies suggested that NO- is released by central neuronal processes that are stimulated by activation of the N-methyl-Daspartate (NMDA) receptor $(9,10)$ and that NMDA receptor activation is associated with activation of sGC and formation of cGMP (11). We have previously shown that NMDA receptors within the nucleus tractus solitarii (NTS) are integral to the baroreceptor reflex (12), and others have suggested that nitroxidergic mechanisms may play a role in cardiovascular control through the NTS (13-17). We have sought to test this hypothesis and determine if NO released from donor compounds elicits cardiovascular responses when administered into the NTS, the primary site of termi-

Table 1 - Effects of NO- donors injected into the NTS

\begin{tabular}{lccc}
\hline & Depressor & No effect & Pressor \\
\hline SNC & ++ & & \\
SNP & \pm & & \\
NO. & \pm & & \\
GSNO & & + & \\
SNAP & & + & \\
GTN & & & \pm
\end{tabular}

nation of vagal and glossopharyngeal cardiovascular afferent nerves.

In our initial studies we assessed effects of unilateral microinjection $(25-50 \mathrm{nl})$ into the NTS of S-nitrosocysteine (SNC), an Snitrosothiol known to release NO. The compound elicited cardiovascular responses that were qualitatively similar to those produced by injection of glutamate or NMDA into the NTS $(12,18,19)$. These findings have been replicated in conscious rats $(20,21)$. Our results seemed consistent with the hypothesis, but we studied the effects of microinjecting other NO. donors at homologous sites in the NTS. Regardless of the doses used (10-1000 pmol), microinjection of S-nitrosoglutathione (GSNO), S-nitrosoacetylpenicillamine (SNAP), sodium nitroprusside (SNP) or glyceryltrinitrate (GTN) into the NTS did not produce responses like those produced by S-nitrosocysteine (250 pmol). In fact, glyceryltrinitrate actually elicited small pressor responses and never depressor responses. Microinjection of a concentrated solution of NO itself did not significantly alter either arterial pressure or heart rate (see Table 1). We confirmed that the injectate contained NO by making similar injections from the same injection system into a closed tube filled with nitrogen and then assessing the presence of $\mathrm{NO} \cdot$ in the tube by the chemiluminescence technique (22).

Because SNC might be acting through a receptor independent of the release of $\mathrm{NO}$, we sought to determine if responses following microinjection of S-nitroso-L-cysteine (L-SNC) differed from those elicited by S-nitroso-Dcysteine (D-SNC). L-SNC elicited dose-dependent (10 to $250 \mathrm{pmol}$ ) transient depressor and bradycardic responses that were significantly greater than those elicited by injection of the dextro-isomer D-SNC at the same site (23). We found that identical amounts of $\mathrm{NO} \cdot$ were released from L- and D-SNC when exposed to homogenates of whole brain tissue. Therefore, the different responses elicited by L- and DSNC were not the result of release of different amounts of NO- by the two isomers. Note that 
S-nitrosothiols were always freshly prepared by standard techniques (24) prior to each experiment. Synthesis was confirmed by spectrophotometry.

To further test if NO released by L-SNC into the extracellular space mediated responses to the S-nitrosothiol, we studied the effects produced by L-SNC before and after injection of oxy- $\left(\mathrm{Fe}^{2+}\right)$ hemoglobin at the same site in NTS. Doses of $5(\mathrm{~N}=5)$ and $40(\mathrm{~N}=6) \mathrm{pmol}$ oxyhemoglobin had no effect on responses to L-SNC ( 250 pmol). The 40-pmol dose would have been sufficient to scavenge as much as $160 \mathrm{pmol}$ of NO$\cdot$ and should have significantly reduced responses to L-SNC were they the result of actions of NO.

Because cleavage of an S-nitrosothiol yields not only nitrogen monoxide but also a disulfide, we sought to determine if cystine, the disulfide product of SNC breakdown, was reponsible for the actions of L-SNC. Microinjection of cystine (50-500 pmol; $\mathrm{N}=4)$ into the NTS did not elicit any significant cardiovascular responses. However, microinjection of the parent thiol, L-cysteine, $(\mathrm{N}=6)$ produced dose-dependent (threshold dose $50 \mathrm{pmol}$; maximally effective dose $500 \mathrm{pmol}$ ) cardiovascular responses like those produced by L-SNC. Unlike responses to L-SNC (250 pmol), whose effects were not altered by prior injection of excitatory amino acid antagonists, responses to L-cysteine (200 pmol) were abolished by injection of kynurenic acid into the NTS. The dose of 1 nmol kynurenic acid selectively blocks responses to ionotropic excitatory amino acid agonists $(12,19)$.

If L-SNC were acting in some way through the NMDA receptor complex, it might have led to activation of sGC in target cells through synthesis of NO (10). We found that responses to L-SNC were significantly reduced by prior microinjection of methylene blue (250 pmol), which inhibits $\mathrm{sGC}$ and formation of cGMP (25). Bilateral microinjection of methylene blue into the NTS also attenuated the Bezold Jarisch reflex elicited by intravenous infusion of serotonin (26). However, methylene blue may also inhibit NOS (27). Therefore, we sought to determine if the blockade of NOS by injection of L-nitroarginine methyl ester (L-NAME; 1 $\mu \mathrm{mol})$ into the NTS altered responses to LSNC (250 pmol) injected at the same site up to 60 min later. The inhibitor had no effect on responses to L-SNC ( $250 \mathrm{pmol})$.

In further studies we confirmed that mechanisms for biosynthesis of NO- are present in the NTS (28). The presence of NOS in NTS neurons and terminal fields was demonstrated by 1) staining for NADPH diaphorase with nitroblue tetrazolium that has been shown to correlate generally with other methods for visualizing the location of NOS (29-31); 2) immunohistochemical methods with an antibody (bNOS antibody, Transduction Labs, Lexington, KY, USA) to rat neuronal NOS, and 3) in situ hybridization for NOS mRNA with a cDNA probe kindly provided by Dr. David Bredt. Such evidence would provide indirect support for the synthesis of S-nitrosothiols that rapidly form by nitrosation of thiol groups by $\mathrm{NO}^{+}$, one of the redox products of NO- itself $(32,33)$. Direct evidence for the synthesis of S-nitrosothiols by the brain has also been provided by a recent report (34). The physiological relevance of nitroxidergic pathways in the NTS has been suggested by others who have shown that NOS is reduced in the NTS after removal of a nodose ganglion $(14,17)$. Thus, vagal afferents, some of which contribute to cardiovascular reflex transmission, may have the capacity to synthesize NO', and by implication, S-nitrosothiols.

We are seeking to determine if these Snitrosothiols bind at specific sites in the CNS. Because SNC is very labile and cysteine is not currently available as a $\left[{ }^{3} \mathrm{H}\right]$-labeled precursor, we have used $\left[{ }^{3} \mathrm{H}\right]-\mathrm{GSNO}$ as a more stable (35) labeled ligand. Using established radioreceptor binding assays, we identified specific, saturable binding of $\left[{ }^{3} \mathrm{H}\right]-\mathrm{GSNO}$ to crude synaptic membrane fractions from whole brain homogenates (36). Unlabeled GSNO displaced binding of the radiolabeled ligand.

L-SNC competed with $\left[{ }^{3} \mathrm{H}\right]$-GSNOfor binding but to a lesser extent than did GSNO (36). 
Thus, $\left[{ }^{3} \mathrm{H}\right]-\mathrm{GSNO}$ may bind to the same site as L-SNC but may have a different affinity for the binding site. However, because there was significant breakdown of SNC during incubation for displacement experiments, it is likely that our experiments underestimated binding affinity of SNC at the GSNO binding site.

In contrast to displacement effected by LSNC, agonists and antagonists acting at glutamate receptors, including L-glutamate, CNQX, 2-AP-5, AP-3, and MK801, did not displace $\left[{ }^{3} \mathrm{H}\right]-\mathrm{GSNO}$ from its binding site. Thus, $\left[{ }^{3} \mathrm{H}\right]$-GSNO binding sites differ from glutamate receptors. This result agrees with the lack of effect of kynurenic acid on cardiovascular responses elicited by L-SNC in the NTS.

Since GSNO did not elicit cardiovascular responses when injected into the NTS but competed with SNC for binding, we sought to determine if GSNO may be an endogenous antagonist for S-nitrosothiol binding sites. Our preliminary studies show that responses to SNC injected into the NTS are significantly reduced by microinjection of GSNO at the same site.

Most studies of nitroxidergic mechanisms in the NTS have used indirect means to assess the physiologic relevance of these mechanisms in cardiovascular reflex control. For example, L-arginine injected into the NTS has been shown to decrease arterial pressure and heart rate (16). Because L-arginine is the substrate upon which NOS acts to synthesize NO• this study was interpreted as supporting a role for NO- in cardiovascular control by the NTS. However, as previously mentioned, an Snitrosothiol formed in the NTS as a result of NO- synthesis could well have been responsible for the responses seen. There are abundant thiols in biological tissues (37) to support such a biosynthetic mechanism. Others have promoted a role for NO in the NTS because of the actions of NOS inhibitors administered into the nucleus $(13,38)$, but the difficulty in measuring authentic NO$\cdot$ and SNC in biological tissues (34) makes the direct application of these findings to $\mathrm{NO}$ as the end product of
NOS risky as well.

Our studies suggest that cardiovascular and autonomic effects elicited by administration of NO- precursors or inhibitors of NOS may relate to effects on production of S-nitrosothiols such as SNC. SNC may exert its action through binding to a site on target cell membranes. In contrast, it is acknowledged that classic receptors for NO· itself do not exist. Thus for NO• it is unclear how specificity of action might occur. Mathematical models suggest that NOmay diffuse from 100 to $1000 \mu \mathrm{m}$ from a point source $(5,39,40)$, which therefore could affect 2 million or more synapses (5). Specificity of action could occur if NO-generating, NOSpositive nerve elements are juxtaposed to nerve elements that contain sGC and form cGMP(4). Indeed, presynaptic terminals containing one of the enzymes are often adjacent to postsynaptic membranes that contain the other (4), but exceptions have been described $(31,41)$.

In fact, if NO- diffuses great distances from its site of release, close apposition of the source with the site of action would be unnecessary. On the other hand, a terminal poised next to a target cell membrane would be consistent with release of a transmitter, perhaps an S-nitrosothiol, that acts at a more traditional receptor. If this were true, $\mathrm{NO} \cdot$ could play a role both as a freely diffusable agent in solution and as a constituent of a more classic transmitter.

The lability of NO- would be one factor limiting the extent of its effects. With a half life generally estimated to be only a matter of seconds (42), NO- forms peroxynitrites, $\mathrm{NO}^{+}$ and $\mathrm{NO}^{-}(33,43)$. One of the potential mechanisms of action of NO- relies upon a oneelectron transfer and formation of the nitrosonium $\mathrm{NO}^{+}$ion which, unlike $\mathrm{NO}$, readily nitrosylates thiols to form S-nitrosothiols $(32,33)$. This nitrosylation of thiols may provide another avenue for specific actions of NO. For example, nitrosylation of the cysteine redox site in the ion channel linked to the NMDA receptor (44) may be the mechanism by which NO• affects that channel (45). On the other hand, thiols, particularly cysteine, glu- 
tathione, and protein thiols, are major components of biological systems where they are found in concentrations of 1-10 $\mathrm{mM}$ (37). Thus, rapid formation of S-nitrosothiols could be expected upon synthesis of NO (37). The Snitrosothiols could concentrate in the cell of origin, the extracellular fluid, and in target cells as well. At any one of these sites they could serve as a reservoir of NO (46). Recent studies have confirmed that the brain synthesizes $S$ nitrosothiols when provided with native thiols (34). S-nitrosothiol synthesis would naturally occur in regions where NO itself is synthesized through actions of NOS on L-arginine (47).

These endogenous S-nitrosothiols may participate in cell to cell signaling independent of their release of NO (48). Like NO these compounds are also labile but, unlike NO·, they may be stored and released in response to stimuli (49). The compounds produce many of the same physiological responses as NO• but their physiological activity is not related to the speed with which they release NO (48). Some S-nitrosothiols pass quickly through cell membranes (24) and, like NO•, activate sGC $(24,49)$, but membrane transport is not essential for their action (24).

In conclusion, although our studies do not rule out a role for $\mathrm{NO}$ - itself in transmission in the NTS, they do suggest a possible direct role for S-nitrosothiols in addition to being an NO. donor. We conjecture that S-nitrosothiols, acting at distinct binding sites, participate in transmission of cardiovascular reflex signals in the NTS of rats. It is unclear whether S-nitrosothiols contribute similarly to signal transduction at other central sites.

\section{References}

1. Amezcua JL, Dusting GJ, Palmer RMJ \& Moncada S (1988). Acetylcholine induces vasodilatation in the rabbit isolated heart through the release of nitric oxide, the endogenous nitrovasodilator. British Journal of Pharmacology, 95: 830-834.

2. Radomski MW, Palmer RMJ \& Moncada $S$ (1987). The role of nitric oxide and cGMP in platelet adhesion to vascular endothelium. British Journal of Pharmacology, 92: 181-187

3. Dawson TM, Dawson VL \& Snyder SH (1992). A novel neuronal messenger molecule in brain: the free radical, nitric oxide. Annals of Neurology, 32: 297-311.

4. Southam E \& Garthwaite J (1993). The nitric oxide-cyclic GMP signalling pathway in rat brain. Neuropharmacology, 32: 1267-1277.

5. Garthwaite J (1995). Neural nitric oxide signalling. Trends in Neurosciences, 18: 51-52.

6. Nathan C \& Xie O (1994). Nitric oxide synthases: Roles, tolls, and controls. Cell, 78: 915-918.

7. De Man JG, Pelckmans PA, Boeckxstaens GE, Bult H, Oosterbosch L, Herman AG \& Van Maercke YM (1991). The role of nitric oxide in inhibitory non-adrenergic noncholinergic neurotransmission in the canine lower oesophageal sphincter. British Journal of Pharmacology, 103: 1092-1096.
8. Knowles RG, Palacios M, Palmer RMJ \& Moncada S (1989). Formation of nitric oxide from L-arginine in the central nervous system: a transduction mechanism for stimulation of the soluble guanylate cyclase. Proceedings of the National Academy of Sciences, USA, 86: 5159-5162.

9. Garthwaite J, Garthwaite G, Palmer RM \& Moncada S (1989). NMDA receptor activation induces nitric oxide synthesis from arginine in rat brain slices. European Journal of Pharmacology, 172: 413-416.

10. East SJ \& Garthwaite J (1991). NMDA receptor activation in rat hippocampus induces cyclic GMP formation through the L-arginine-nitric oxide pathway. Neuroscience Letters, 123: 17-19.

11. Southam E, East SJ \& Garthwaite J (1991). Excitatory amino acid receptors coupled to the nitric oxide/cyclic GMP pathway in rat cerebellum during development. Journal of Neurochemistry, 56: 2072-2081.

12. Ohta H \& Talman WT (1994). Both NMDA and non-NMDA receptors in the NTS participate in the baroreceptor reflex in rats. American Journal of Physiology, 267: R1065-R1070.
13. Harada S, Tokunaga S, Momohara M Masaki H, Tagawa $T$, Imaizumi $T$ \& Takeshita A (1993). Inhibition of nitric oxide formation in the nucleus tractus solitarius increases renal sympathetic nerve activity in rabbits. Circulation Research, 72: 511-516.

14. Lü Y, Ding Y-Q, Qin B-Z \& Li J-S (1994). The distribution and origin of axon terminals with NADPH diaphorase activity in the nucleus of the solitary tract of the rat. Neuroscience Letters, 171: 70-72.

15. Zanzinger J, Czachurski J \& Seller $\mathrm{H}$ (1995). Effects of nitric oxide on sympathetic baroreflex transmission in the nucleus tractus solitarii and caudal ventrolateral medulla in cats. Neuroscience Letters, 197: 199-202.

16. Tseng CJ, Liu HY, Lin HC, Ger LP, Tung CS \& Yen MH (1996). Cardiovascular effects of nitric oxide in the brain stem nuclei of rats. Hypertension, 27: 36-42.

17. Ruggiero DA, Mtui EP, Otake K \& Anwar $M$ (1996). Central and primary visceral afferents to nucleus tractus solitarii may generate nitric oxide as a membranepermeant neuronal messenger. Journal of Comparative Neurology, 364: 51-67. 
18. Lewis SJ, Ohta H, Machado BH, Bates JN \& Talman WT (1991). Microinjection of Snitrosocysteine into the nucleus tractus solitarii decreases arterial pressure and heart rate via activation of soluble guanylate cyclase. European Journal of Pharmacology, 202: 135-136.

19. Talman WT (1989). Kynurenic acid microinjected into the nucleus tractus solitarius of rat blocks the arterial baroreflex but not responses to glutamate. Neuroscience Letters, 102: 247-252.

20. Machado BH \& Bonagamba LGH (1992). Microinjection of S-nitrosocysteine into the nucleus tractus solitarii of conscious rats decreases arterial pressure but Lglutamate does not. European Journal of Pharmacology, 221: 179-182.

21. Lewis SJ, Davisson RL, Bates JN, Johnson AK, Ohta H \& Talman WT (1992). Stereoselective actions of S-nitrosocysteine $(\mathrm{SNC})$ suggests the presence of specific S-nitrosothiol receptors. FASEB Journal, 6: A1165.

22. Myers PR, Minor Jr RL, Guerra Jr R, Bates JN \& Harrison DG (1990). Vasorelaxant properties of the endothelium-derived relaxing factor more closely resemble Snitrosocysteine than nitric oxide. Nature, 345: 161-163.

23. Ohta H, Bates JN, Lewis SJ \& Talman WT (1996). Actions of s-nitrosocysteine in the nucleus tractus solitarii are unrelated to release of nitric oxide. Brain Research (in press).

24. Mathews WR \& Kerr SW (1993). Biological activity of S-nitrosothiols: The role of nitric oxide. Journal of Pharmacology and Experimental Therapeutics, 267: 15291537.

25. Martin W, Villani GM, Jothianadan D \& Furchgott RF (1985). Selective blockade of endothelium-dependent and glyceryl trinitrate-induced relaxation by hemoglobin and by methylene blue in the rabbit aorta. Journal of Pharmacology and Experimental Therapeutics, 232: 708-716.

26. Lewis SJ, Machado BH, Ohta H \& Talman WT (1991). Processing of cardiopulmonary afferent input within the nucleus tractus solitarii involves activation of soluble guanylate cyclase. European Journal of Pharmacology, 203: 327-328.

27. Mayer B, Brunner F \& Schmidt K (1993). Inhibition of nitric oxide synthesis by methylene blue. Biochemical Pharmacology, 45: $367-374$
28. Lin L-H, Boutelle S, Sandra A \& Talman WT (1995). Changes in expression of nitric oxide synthase in the dorsal vagal complex after nodose ganglionectomy or vagotomy in rat. Society for Neuroscience Abstracts, 21: 625.

29. Hope BT, Michael GJ, Knigge KM \& Vincent SR (1991). Neuronal NADPH diaphorase is a nitric oxide synthase. Proceedings of the National Academy of Sciences, USA, 88: 2811-2814.

30. Nakos G \& Gossrau R (1994). When NADPH diaphorase (NADPHd) works in the presence of formaldehyde, the enzyme appears to visualize selectively cells with constitutive nitric oxide synthase (NOS). Acta Histochemica, 96: 335-343.

31. Schmidt HHHW, Gagne GD, Nakane M, Pollock JS, Miller MF \& Murad F (1992). Mapping of neural nitric oxide synthase in the rat suggests frequent co-localization with NADPH diaphorase but not with soluble guanylyl cyclase, and novel paraneural functions for nitrinergic signal transduction. Journal of Histochemistry and Cytochemistry, 40: 1439-1456.

32. Stamler JS (1994). Redox signaling: Nitrosylation and related target interactions of nitric oxide. Cell, 78: 931-936.

33. Stamler JS, Singel DJ \& Loscalzo J (1992). Biochemistry of nitric oxide and its redoxactivated forms. Science, 258: 1898-1902.

34. Kluge I, Gutteck-Amsler U, Cuénod M \& Do KQ (1995). S-nitrosoglutathione is endogenous in rat cerebellum. Society for Neuroscience Abstracts, 21: 626.

35. Kowaluk EA \& Fung H (1990). Spontaneous liberation of nitric oxide cannot account for in vitro vascular relaxation by Snitrosothiols. Journal of Pharmacology and Experimental Therapeutics, 255: 1256-1264.

36. Taguchi J, Ohta H \& Talman WT (1995). Identification and pharmacological characterization of an S-nitrosoglutathione binding site in rat brain. Society for Neuroscience Abstracts, 21: 626.

37. Arnelle DR \& Stamler JS (1995). $\mathrm{NO}^{+}$, $\mathrm{NO}^{*}$, and NO- donation by $S$-nitrosothiols: Implications for regulation of physiological functions by S-nitrosylation and acceleration of disulfide formation. Archives of Biochemistry and Biophysics, 318: 279285.

38. Ma S, Abboud FM \& Felder RB (1995). Effects of L-arginine-derived nitric oxide synthesis on neuronal activity in nucleus tractus solitarius. American Journal of Physiology, 268 (Regulatory, Integrative and Comparative Physiology): R487R491.
39. Garthwaite J \& Boulton CL (1995). Nitric oxide signaling in the central nervous system. Annual Review of Physiology, 57: 683-706.

40. Schuman EM \& Madison DV (1994). Nitric oxide and synaptic function. Annual Review of Neuroscience, 17: 153-183.

41. Zhang J \& Snyder SH (1995). Nitric oxide in the nervous system. Annual Review of Pharmacology and Toxicology, 35: 213233.

42. Feelisch M, Te Poel M, Zamora R, Deussen A \& Moncada S (1994). Understanding the controversy over the identity of EDRF. Nature, 368: 62-65.

43. Pryor WA \& Squadrito GL (1995). The chemistry of peroxynitrite: A product from the reaction of nitric oxide with superoxide. American Journal of Physiology, 268 (Lung Cellular and Molecular Physiology): L699-L722.

44. Sullivan JM, Traynelis SF, Chen H-SV, Escobar W, Heinemann SF \& Lipton SA (1994). Identification of two cysteine residues that are required for redox modulation of the NMDA subtype of glutamate receptor. Neuron, 13: 929-936.

45. Lei SZ, Pan Z-H, Aggarwal SK, Chen H-SV Hartman J, Sucher NJ \& Lipton SA (1992). Effect of nitric oxide production on the redox modulatory site of the NMDA receptor-channel complex. Neuron, 8: 10871099

46. Stamler JS, Jaraki O, Osborne J, Simon DI, Keaney J, Vita J, Singel D, Valeri CR \& Loscalzo J (1992). Nitric oxide circulates in mammalian plasma primarily as an $S$ nitroso adduct of serum albumin. Proceedings of the National Academy of Sciences, USA, 89: 7674-7677.

47. Moncada S (1992). The 1991 Ulf von Euler lecture. The L-arginine:nitric oxide pathway. Acta Physiologica Scandinavica, 145: 201-227.

48. Gaston B, Drazen JM, Jansen A, Sugarbaker DA, Loscalzo J, Richards W \& Stamler JS (1994). Relaxation of human bronchial smooth muscle by S-nitrosothiols in vitro. Journal of Pharmacology and Experimental Therapeutics, 268: 978-984.

49. Ignarro LJ (1990). Nitric oxide: a novel signal transduction mechanism for transcellular communication. Hypertension, 16: 477-483. 